\title{
Immunomodulatory Potential of Gemmomodified Extract of Terminalia arjuna
}

\author{
NazishJahan ${ }^{\mathrm{a} *}$, Khalil-ur- Rahman $^{\mathrm{b}}$ Sajjad-ur- Rahman $^{\mathrm{c}}$ and Fareeha Kousar ${ }^{\mathrm{a}}$ \\ ${ }^{a}$ Department of Chemistry, University of Agriculture, Faisalabad, Pakistan \\ ${ }^{b}$ Department of Biochemistry, University of Agriculture, Faisalabad, Pakistan \\ ${ }^{c}$ Institute of Microbiology, University of Agriculture, Faisalabad, Pakistan
}

\begin{abstract}
In recent years there is increasing interest in the field ofmodulation of immune by plant products. The aim of this study was to evaluate the immunomodulatory potential of bark and gemmomodified extracts of Terminalia arjuna.Gemmotherapy is a new form of therapy in which super active form of medicines, made from freshly growing parts are used for the treatment of various diseases. Effect of extracts of T. arjuna on cellmediated and humoral immune reposes was evaluated by phagocytosis and haemagglutination assays respectively.Macrophages engulfment and antibody production was stimulated after the induction of both extract of T. arjuna however, bark extract showed slightly greater immunostimulatory effect as compared to gemmomodified extract. Both extracts of Terminalia arjuna (methanolic bark and gemmo modified) were found considerably effective in boosting cell mediated (Phagocytosis) and humoral immune response.
\end{abstract}

Key Words:Phagocytosis, Terminalia arjuna, Immunomodulatory

\section{Introduction}

The immune system is defense system of the body that provides protection against foreign invaders, which are disease causing microbes (bacteria, parasite and fungi). Plant based drugs have been intensified all over the world. One of the main strategies of herbal treatment is to increase the body's natural resistance to disease/stress causing agents rather than directly neutralizing the agents itself in practice. Plant origin immunomodulatory agents enhanced para immunity, non specific immunomodulation of granulocytes, macrophages, natural killer cells and complement functions ${ }^{1-6}$.

Immune diseases are big problem for mankind. Immunomodulatory therapy is recognized as important alternate to conventional chemotherapy in many diseases. Use of plant compounds to enhance the phagocytosis ability of macrophages and increase antibody production has been well documented by many researchers ${ }^{2,4,5,-9}$. The use of plant products as immunomodulator is still in developing stage ${ }^{10-12}$.A variety of phytochemicals such as polysaccharides ${ }^{13}$ and flavonoids ${ }^{14}$ have been reported to modulate the immune system.

Beside conventional herbal medicines gemmotherapy is emerging and less studied field. Gemmotherapy is fabulous active form of medicine, made from embryonic tissues of various trees and shrubs (buds and young shoots), reproductive parts and newly grown tissues. The powerful medicinal potential of fresh germinating parts of plants is getting attention of scientists working in various disciplines ${ }^{15}$. Terminalia arjuna is versatile traditional medicinal plant Clinical studies suggested that $T$. arjuna is effective in patient of stable angina ${ }^{16}$. It improves the blood circulation to heart, regulate blood pressure ${ }^{17}$ used for treatment of hypercholesterolemia ${ }^{15,18-19}$ and inhibited the platelet aggregation ${ }^{20}$.

Little work has been done on immunomodulatory activity of Terminalia arjuna.It is need of time to develop alternative therapies for treatment of immune disease therefore, this project has been designed to explore the important immunomodulatory potential of gemmomodified and bark extracts of Terminalia arjuna.

\section{Extract preparation}

\section{Materials and methods}

Bark extract

The bark powdered $(30 \mathrm{~g})$ of Terminalia arjunawas refluxed with methanol. After completion of time extract was filtered and methanol was evaporated under reduced pressure to get crude extract and stored in refrigerator at $4^{\circ} \mathrm{C}$ for further use in analysis

\section{Gemmo modified extract}

Paste of plant material (100g), which is freshly harvested from plants during their growing stage was macerated with one liter mixture of glycerin and methanol in a ratio of 1:2 and shake vigorously. After one month macerate was filtered and solvent was removed with rotary evaporator and crude extract was stored.

\section{Evaluation of Phagocytosis Activity}

Different steps involved in evaluation of cell phagocytosis assay are as follow: 


\section{Collection of Abdominal Exudate Cells}

The abdominal exudate cells (AEC) were acquired from the grown-up (age 4 weeks) chickens. Sephadex granules G-50 (3\%, w/v) were suspended in normal saline solution $(0.85 \%)$. Suspension of Sephadex granules was injected into chickens intra peritoneally at the dose of one $\mathrm{mL}$ per $100 \mathrm{~g}$ b.wt. After $48 \mathrm{hrs}$ of Sephadex injection, the abdominal cavity was lavaged with heparin $(0.5 \mathrm{U} / \mathrm{mL})$ and normal saline $(0.85 \%)$. AEC were obtained aseptically from three different chickens and combined for further investigation. AEC suspension was washed two times with medium (M-199, Merck USA), the medium was accessorized with fetal calf serum $(5 \%)$ and two antibiotics including penicillin $(100$ unit $/ \mathrm{mL})$ and streptomycin $(50 \mu \mathrm{g} / \mathrm{mL})$. The viability of AEC was confirmed with the use of trypan blue (dye) and the concentration of $1 \times 10^{6} \mathrm{AEC}$ per $\mathrm{mL}$ was finally preserved in sterilized RPMI-1640 medium ${ }^{21}$ (SANDHU et al., 2006).

\section{Preparation of Extract Dilutions}

Three different concentrations of Terminalia arjunaextracts from were diluted serially as 10 fold dilutions. Sterilized double distilled water was used for the preparation of dilutions. Double distilled water (9 $\mathrm{mL}$ ) was taken in three test tubes separately. One $\mathrm{mg}$ of respected extracts was transferred into ${ }^{\text {st }}$ test tube and mixed vigorously at ambient temperature. One $\mathrm{mL}$ of the content from first test tube was transferred to second test tube, mixed for one min at ambient temperature and one $\mathrm{mL}$ solution was again transferred from $2^{\text {nd }}$ tube into the $3^{\text {rd }}$ test tube maintaining 10 fold serial dilutions and each dilution contained $100,10,1 \mu \mathrm{g} / \mathrm{m} \mathrm{L}$. of plant extract respectively. All the diluted extract samples were stored below $10^{\circ} \mathrm{C}$ for further use.

\section{Phagocytosis Assay}

Phagocytosis assay was performed according to the method reported by SANDHUetal. (2006). For this assay sterilized petri dishes with five round glass cover slips per extract was prepared in duplicate. Already filtered and sterilized RPMI-1640 cell culture medium $(15 \mathrm{~mL})$ was transferred into Pyrex glass petri dishes. Two $\mathrm{mL}$ of AEC suspension was shifted to each petri dish slightly mixed and kept under incubation with $10 \%$ $\mathrm{CO}_{2}$ into incubator for $3 \mathrm{~h}$.

Glass cover slips were washed with sterilized RPM1-1640 medium and maintained into freshly changed medium in the Petri dishes. One Petri dish for each group was reserved as untreated controlled where as the other petri dishes having five glass cover slips was provided with one $\mathrm{mL}$ of diluted phenolics fractions, after gentle mixing, the petri dished were kept for incubation at $37^{\circ} \mathrm{C}$ for 45 minutes. Washed sheep RBCs suspension $(2 \mathrm{~mL}, 1 \%)$ was transferred separately in all Petri dishes and further incubated for $1 \mathrm{~h}$ at $37^{\circ} \mathrm{C}$. The cover slips were separated from culture medium and unphagocytos RBCs was removed by single washing with normal saline $(0.85 \%)$. The macrophages cells were preserved in methanol and the stained with the help of Dip Quick and placed on clean glass slides Engulfed macrophages were calculated according to formula:

Average number of RBCs engulfed by macrophages

$\%$ of macrophages engulfed =

\section{Determination of Humoral Antibody Titer}

Average no. of adhering macrophages

The effect of Terminalia arjuna extractson antibody response was evaluated by the humoral antibody response in rabbits against sheep RBCs that served as non specific antigen in treated and untreated experimental groups.

\section{Experimental Protocol}

Male albino rabbits were selected for this study and animals were kept under standard condition of environment, water and diet. Rabbits were divided into different experimental groups

Group 1; normal controls; rabbits were administered standard diet only.

Group 2; .Antigen control, rabbits of this group was immunized with SRBC (sheep red blood cell) injected subcutaneously on 1 st and $3^{\text {rd }}$ day.

Group 3; $100 \mathrm{mg} / \mathrm{kg}$ plant extract was given to this group daily for 14 days

Group $4 ; 200 \mathrm{mg} / \mathrm{kgbw}$ plant extract was given daily for 14 days.

Group 5; these rabbits were first immunized with RBCs on $1^{\text {st }}$ and $3^{\text {rd }}$ day after immunization the plant extract $(100 \mathrm{mg} / \mathrm{kg}$ b.wt $)$ was given for 14 days.

Group 6; Rabbits were treated as group 5 then dose of plant extract (200mg/kgb.wt) was given for 14 days

\section{Haemagglutination Assay}

Serum was separated from blood of different experiment groups at the end of experimental period. Antibody titer was evaluated by Haemagglutination assay. Serial bifold dilution of serum in 96 wall micro titer plates was 
prepared with normal saline, then fresh SRBCs $(1 \%, 25 \mathrm{ul})$ was shifted into each dilution and mixed softly then left the plates for $1 \mathrm{~h}$. After completion the time anti body titer in terms of highest dilution of serum sample with haemagglutination was noted. Mean $\log _{2}$ of the titer was determined to compare the results ${ }^{10}$.

\section{Statistical Analysis}

Each sample was analyzed in triplicate and data is expressed as mean \pm SD.

Data was analyzed using analysis of variance ANOVA in SPSS 15 software. Tukey Multiple Comparison test was used for comparison of means of different experiments $(\mathrm{p}<0.05)$

\section{Results \& Discussion}

\section{Effect of Plant Treatment on Phagocytosis}

Peritoneal macrophages treated with different doses of plant extracts were evaluated for their capabilities to digest and ingest particle and have been shown in (Fig 1). The treatment with methanolic bark and gemmo modified extract of Terminalia arjuna significantly increased the number of SRBC engulfed by macrophages in dose dependent manner. Macrophages engulfed $25 \pm 2.91$ and 23.2 \pm 3.115 SRBC after induction of bark and gemmomodified extract of Terminalia arjuna respectively at the concentration of 100 $\mu \mathrm{g} / \mathrm{mL}$. Number of engulfed cells was significantly higher $(\mathrm{p}<0.05)$ than untreated control $(1.6 \pm 0.25)$. Moreover, after the treatment with both extracts of Terminalia arjuna bark and gemmomodified the macrophages engulfment percentage $(\%$ phagocytosis $)$ was significantly $(p<0.05)$ higher $(95.367 \pm 1.9,93.9 \pm$ $1.00 \%$ ) than control $(39.8 \pm 0.40 \%$ Fig \# 2). Significant immune stimulatory effect of Terminalia arjun extract

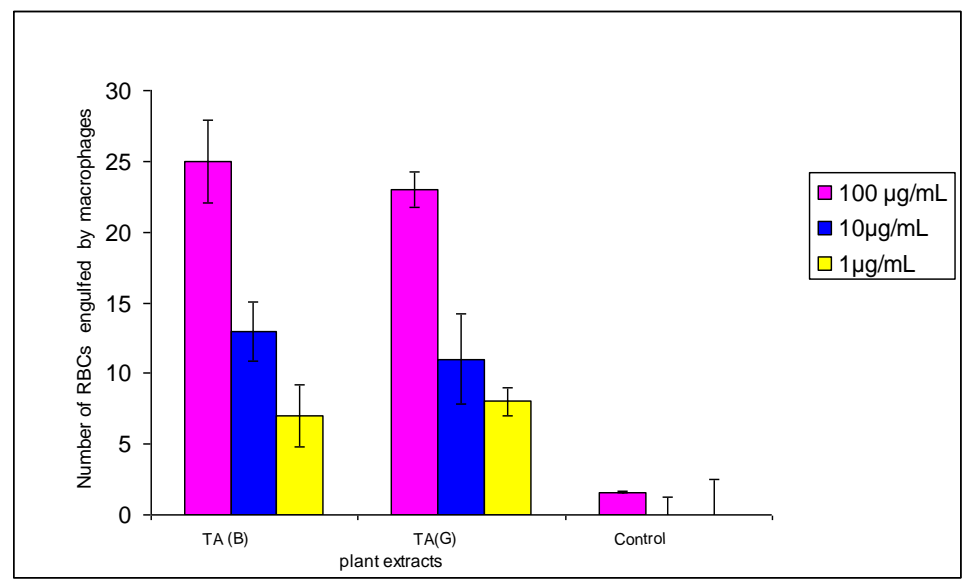

Fig 1.Macrophages engulfment factor with different concentrations of Terminalia arjuna extracts All values expressed as mean \pm SD $(n=3)$ Significant. Terminalia arjuna Bark extract, $\mathrm{TA}(\mathrm{G})=$ Terminalia arjuna gemmo extract

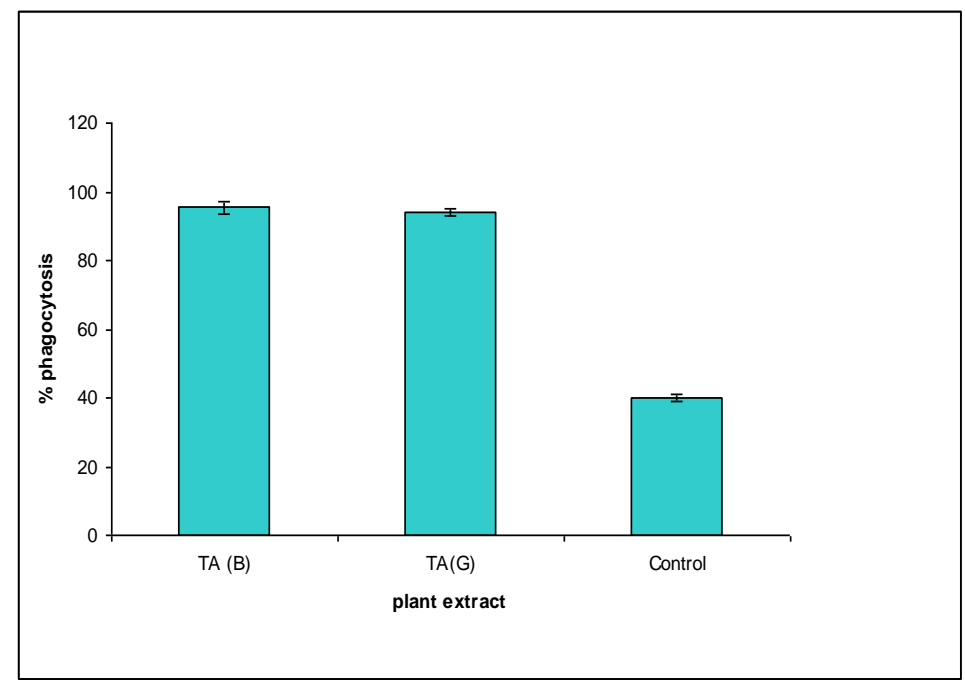

Fig 2.Percentage (\%) Phagocytosis after treatment with extracts of Terminalia arjuna

All values expressed as mean $\pm \mathrm{SD}(\mathrm{n}=3)$. TA $(\mathrm{B})=$ Terminalia arjuna Bark extract, $\mathrm{TA}(\mathrm{G})=$ Terminalia arjuna gemmo extracton Phagocytosis was observed when compared with control. 


\section{Effect of Different Plant Extract on Humoral Antibody Titer}

Both extracts exhibited stimulation of antibody production dose dependently, but different in extent (Table 1). Terminalia arjuna bark extract $(200 \mathrm{mg} / \mathrm{kg}$ b.wt) significantly $(\mathrm{p}<0.05)$ increased the humoral antibody titer (11.5 \pm 2.062$)$ after immunization of rabbits with RBCs in comparison of normal control (4.25 \pm $0.50)$ and antigen control $(6.5 \pm 0.57)$. Mean antibody titer for gemmo modified extract of Terminalia arjuna treated rabbits was $11.00 \pm 1.00$, which was significantly $(\mathrm{P}<0.05)$ higher than control $(4.25 \pm 0.50)$. Terminalia arjuna both gemmomodified and bark extracts showed almost similar effect on antibody titer.

Modulation of immune system (stimulation and suppression) is important strategy in therapy of many diseases. A number of research studies have been shown plant product's multiple actions on defense system responses ${ }^{4,6,12,22-24,30}$. Macrophages are involved in the commencement of different immune response including innate and adaptive immunity. They play crucial role to engulf and digest (phagocytose) cellular trash and microbial invaders. Phagocytosis is important ability of macrophages, and when this is disturbed it results in increase risk of infections. Antibodies are specific immune proteins and their production is major function of immune system as they have ability to combine with antigens that can activate their production. The antibody titer is helpful to determine the changes in the quantity of antibodies in the route of immune reaction. Humoral antibody titer as well as cell mediated immunity (Phagocytosis) are very important parameters to check the efficiency of immune system.

Both extracts of Terminalia arjuna (methanolic bark and Gemmo modified) were found to be substantially effective in boosting cell mediated (Phagocytosis) and humoral immune response (antibody titer). The treatment of the both extracts of Terminalia arjuna methanolic bark and gemmo modified at different level of doses $(100,200 \mathrm{mg} / \mathrm{kg} \mathrm{b}$.wt.) increased the antibody production and significantly enhanced the phagocytosis ability of macrophages. Humoral antibody titer and phagocytosis are important parameter to evaluate the effect of medicinal plants on immune system.Many scientists reported the effect of plant extracts on antibody titer and phagocytosis activity ${ }^{5,25-27}$. The increase in engulfment ability of macrophages and antibodies production may be due to the immunostimulatory effect of Terminalia arjuna extracts. Immunomodulatory effect of medicinal plants has been attributed to polyphenols (antioxidant components). Flavonoids and polyphenols have been renowned to possessImmunomodulatory potential ${ }^{28}$. Different studies confirmed the strong antioxidant behavior and high polyphenolic contents ofTerminalia arjuna. Significantly higher immunostimulatory effect of Terminalia arjuna links to its higher antioxidant power and polyphenolic contents. These results are in agreements with some previous reports about immunostimulatory effect of polyphenols ${ }^{9}$.

Immunomodulatory effect of Terminalia arjuna was reported in literature but no scientific study was available in this regard and this study can provide scientific validation of immunostimulatory potential of Terminalia arjuna. From these results it is concluded Terminalia arjunaexhibited high immunostimulatory effect. Both extracts boosted the cell-mediated as well as humoral immune responses.

Table 1Effect of Terminalia arjuna extracts treatment on humoral antibody Titer in different experimental groups of rabbits

\begin{tabular}{|l|l|l|l|l|l|l|}
\hline Groups & $\begin{array}{l}\text { G1 } \\
\text { Normal } \\
\text { Control }\end{array}$ & $\begin{array}{l}\text { G2 } \\
\text { (Positive } \\
\text { control) }\end{array}$ & $\begin{array}{l}\text { G3 } \\
\mathbf{1 0 0} \mathbf{~ m g} / \mathbf{k g} \\
\text { (Plant } \\
\text { extract) }\end{array}$ & $\begin{array}{l}\text { G4 } \\
\mathbf{2 0 0} \mathbf{~ m g} / \mathbf{k g} \\
\text { (Plant } \\
\text { extract) }\end{array}$ & $\begin{array}{l}\text { G5 } \\
\mathbf{1 0 0} \mathbf{~ m g} / \mathbf{k g} \\
\text { (Plant } \\
\text { extract }+ \\
\text { antigen) }\end{array}$ & $\begin{array}{l}\text { G6 } \\
\mathbf{2 0 0} \mathbf{~ m g} / \mathbf{k g} \\
\text { (Plant } \\
\text { extract + } \\
\text { Antigen) }\end{array}$ \\
\hline $\begin{array}{l}\text { T. arjuna } \\
\text { (bark) }\end{array}$ & $4.250 \pm 0.500$ & $6.5 \pm 0.577$ & $4.7 \pm 50.500$ & $5.0 \pm 0.578$ & $10.75 \pm 0.577^{*}$ & $11.5 \pm 2.062^{* *}$ \\
\hline $\begin{array}{l}\text { T. arjuna( } \\
\text { gemmo) }\end{array}$ & $4.30 \pm 0.300$ & $6.2 \pm 0.277$ & $4.5 \pm 1.5$ & $4.75 \pm 1.00$ & $10.00 \pm 1.155^{*}$ & $11.00 \pm 1.0^{* *}$ \\
\hline
\end{tabular}

All values expressed as mean $\pm \mathrm{SD}(\mathrm{n}=3)$. 


\section{References}

[1]. Djafoua, Y. M. R. S.Mouokeu, C.Tume, M. O.Kamtchueng and J.R. Kuiate.( 2015) Immunomodulatory activity of methanol leaf extracts of Cameroonian medicinal plants. J Complement Integr Med. 12(4): 267-275.

[2]. Mashitha V.P., J.A.Rudra, and A. Upadhyay. (2015). Immunomodulatory potential from Asparagus racemosus tissue cultures. J Nat Sci BiolMedJul-Dec; 6(2): 415-420.

[3]. Arulkumaran, S., Ramprasath, V. R., Shanthi and Sachanandam, P. (2007). Free radical quenching and immunomodulatory effect of a modified siddha preparation, kalpaarnruthaa. J. of Health Sci. 53: 170-176.

[4]. Jeba, R. C., Vaidyanathan, R. and Rameshkumar, G. (2011). Efficacy of ocimumbasilicum for immunomodulatory activity in wistar albino rat. Int. J. Pharm. Pharm. Sci. 3: 199-703.

[5]. Kumar, S. V., Sharma, P. K., Dudhe, R. and Kumar, N. (2011). Immunomodulatory effect of some traditional medicinal plant. J. Chem. Pharm. Res. 3: 675-689.

[6]. Saravanana, S., Babua, N. P., Pandikumara, P., Raja, M. K., Paulraja, M. G., Ignacimuthua, S. (2012). Immunomodulatory potential of Enicostemaaxillare (Lam.) A. Raynal, a traditional medicinal plant. J. Ethnopharm. 140: $239-24$.

[7]. Jayathirtha, M. G. and Mishra, S. H. (2004). Preliminary immunomodulatory activities of methanol extracts of Ecliptaalba and Centellaasiatica. Phytomedicine. 11: 361-365.

[8]. Gabhe, S. Y., Tatke,P. A. and Khan, T. A. (2006). Evaluation of the immunomodulatory activity of methanol extract of ficusBenghalensisroots in rats. Ind. J. Pharmacol. 38: 271-275.

[9]. Kannam, M. and Singh, R. A. J. (2010). An Immunopharmacological investigation of indian medicinal plant Nyctanthesarbertristis.World. appl. sci. J. 11: 495-503.

[10]. Amirghofran, Z., Azadmehr, A., Bahmanim, M. and Javidnia, K. (2008). Stimulatory effect of Euophorbiacheiradenia on cell mediated immunity and humoral antibody synthesis. Iran J. Immunol. 5:115-121.

[11]. Ranjith, M. S., Ranjitsingh, A. J. A., Shankar, S. G., Vijayalaksmi, G. S., Deepa, K. and Sindu, H. S. D. (2008). Enhanced phagocytosis and antibody production by Tinosporacordifolia. A new dimension in immunomodulation. Afri. J. Biotech. 7: 81-85.

[12]. Upadhyaya R, Pandey RP1, Sharma V and VermaAK (2011).Assessment of the Multifaceted Immunomodulatory Potential of the Aqueous Extract of TinosporaCordifolia. Res. J. Chem. Sci. 1: 71-79.

[13]. Shin, J. Y., Song, J., Yun, Y. S., Yong, D., Rhee, K. and Pyo, S. (2002). Immunostimulating effects of acidic polysaccharide extract of panax ginseng on macrophage function. Immunopharmacol. andImmunotoxicol. 24: 469-482.

[14]. Zhao, M., Yang, B., Wang, J., Liu, Y., Yu, L. and Jiang, Y. (2007).Immunomodulatory and anticancer activities of flavonoids extracted from litchi (Litchichinensis Sonn.) pericarp. Int. Immunopharmacol. 7: 162-166.

[15]. Jahan, N. Rehman, K., Ali S. and Bhatti I. A.( 2011). Antioxidant activity of gemmotherapeutically treated indigenous medicinal plants. Asian Journal of Chemistry, 23(8);3461-3470

[16]. Dwivedi, S. and Agarwal, M. P. (1994). Anti-anginal and cardioprotective effects of Terminalia arjuna, and indigenous drug in coronary heart disease. J. Assoc. Physi. Ind. 42: 287-289.

[17]. Nammi, S., Gudavalli, R., Babu, B. S. R., Lodagala, D. S. and Boini, K. M. (2003). Possible mechanisms of hypotension produced $70 \%$ alcoholic extract of Terminalia arjuna (L.) in anaesthetized dogs. Complement and Alt. Med. 3: 5.

[18]. Ram, A., Lauria, P., Gupta, R., Kumar, P. and Sharma, V. N. (1997). Hypocholesterolaemic effects of Terminalia arjuna tree bark.J. of Ethnopharmacol. 55: 165-169.

[19]. Chander, R., Singh, K., Khanna, A. K., Kaul, S. M., Puri, A., Saxena, R., Bhatia, G., Rizvi, F. and Rastogi, A. K. (2004).Antidyslipidemic and antioxidant activities of differentfractions of Terminalia arjunastem bark.Ind. J. of Clin. Biochem. 19: $141-148$

[20]. Namita, M., Veena, D., Ajay, B. and Deepak, B. (2009). Inhibitory effects of Terminalia arjuna on platelet activation in vitro in healthy subjects and patients with coronary artery.Platelets. 20: 183-190.

[21]. Sandhu, M. A., Rahman, Z. U. and Rahman, S. A. (2006). Dynamics of macrophages in laying hens during second and third production cycle after zinc induced molting. The J. poultry sci. 43: 286-295.

[22]. Tiwari, A. K., Gode, J. D. and Dubey, G. P. (1990). Effect of Terminalia Arjuna on lipid profiles of rabbits fed hypocholesterolemic Diet. Pharmaceutical Biol. 28: 43-47.

[23]. NehaJand Mishra, R. N. (2011). Immunomodulatory activity of Trikatumegaext. Int.J.of Res in pharm and Med Sci. 2: 160-164.

[24]. Tsai, K. D., Lin, B. R., Perng, D. S., Wei, J. C., Yu, Y. W. and Cherng, J. (2011). Immunomodulatory effects of aqueous extract of Ocimumbasilicum (Linn.) and some of its constituents on human immune cells. J. Med. Plant Res. 5: 1873-1883.

[25]. Gokani, R. H., Lahiri, S. K., Santani, D. D. and Shah, M. B. (2007).Evaluation of immunomodulatory activity of Clerodendrumphlomidisand Premnaintegrifolia. Int. J. Pharmacol.3: 352-356.

[26]. Biella, C. A., Salvador, M. J., Dias, D. A., Baruffi, M. D. and Crot, L. S. P. (2008). Evaluation of immunomodulatory and antiinflammatory effects and phytochemical screening of AlternantheratenellaColla (Amaranthaceae) aqueous extracts.Mem. Inst. Oswaldo. Cruz. 103: 569-572.

[27]. Gaur, K., Kori, M. L. and Nema, R. K. (2009).Comparative Screening of Immunomodulatory Activity of Hydro-alcoholic Extract of Hibiscus rosasinensis Linn. and ethanolic extract of Cleome gynandra Linn. Global J. Pharmacol. 3: 85-89.

[28]. Chiang, L. C., Ng, L. T., Chiang, W., Chang, M. Y. and Lin, C. C. (2003) Immunomodulatory activities of flavanoidsmonoterpenoids triterpenoids, iridoids, glycosides and phenolic compounds of plantagospecies. Plant Med. 69: 600-604.

[29]. Sternberg, Z., Chadha, K.Lieberman, A. DrakeA.Hojnacki,D.GuttmanB. W. K.and Munschauer. F.(2009). Immunomodulatory responses of peripheral blood mononuclear cells from multiple sclerosis patients upon in vitro incubation with the flavonoid luteolin: additive effects of IFN- $\beta$. J. Neuro. Inflam. 6:28-33.

[30]. Ahirwal L., S. Singh, Manish K. D, Vandana B., Archana M. and Shruti S.,(2015). In Vivo Immunomodulatory Effects Of The Methanolic Leaf Extract Of GymnemaSylvestre In Swiss Albino Mice. Arch. Biol. Sci., Belgrade. 67(2), 561-570. 